\title{
Size of the Mueller-Lyer illusion as a function of its dimensions: Theory and data
}

\author{
FRANK RESTLE and JAMES DECKER \\ Indiana University, Bloomington, Indiana 47401
}

\begin{abstract}
In tests with naive subjects, it was found that: the apparent length of a test shaft (1) increases with angle of wing to shaft to a maximum of about $160^{\circ}$ (wings out), and (2) is an inverted-U function of wing length, with maximum when wing length equals shaft length; (3) all effects are approximately proportional to shaft length; and (4) the angle exerts its effect within a small region near the tip of the shaft, the region extending about one-seventh the shaft length. The effects apparently do not result from simple distortion of the retinal image, but some may result from assimilation or confusion in coding image into lengths, and some effects apparently arise as lengths are combined into judgments. The new data are shown to agree in quantitative detail with results collected from 1896 to the present.
\end{abstract}

The Mueller-Lyer arrowhead illusion is one of the most famous and familiar of the geometrical-optical illusions, and many theories of vision have offered explanations of it. One reason to emphasize the Mueller-Lyer illusion is that there are many variations of it, and careful experiments have determined the stimulus dimensions that give rise to the largest illusion.

Heymans (1896) varied both the angle of wings to stem and the length of wings, using a version of the figure including both wings in and wings out together, as in Figure 1. This figure measures the contrast between wings in and wings out but cannot measure any change affecting both equally.

Two major facts emerge from Heymans' measurements. One is the functional relationship between the angle of wings to stem and the magnitude of the illusion. If the wings are at $90^{\circ}$ to the stem, in Heymans' form of the figure, there is no basis for an illusion. The wings cannot be placed at an angle of $0^{\circ}$ to the stem without lying on it, and the most acute angle that can be used is determined in large part by the fineness of lines used. Heymans stopped at a figure with angles of $10^{\circ}$ and $170^{\circ}$.

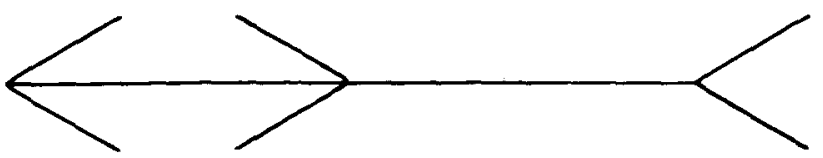

Figure 1. Typical display of the double Mueller-Lyer figure.

The experimental research in this paper was supported in part by Grant MH-16817 from the Public Health service to the first author.

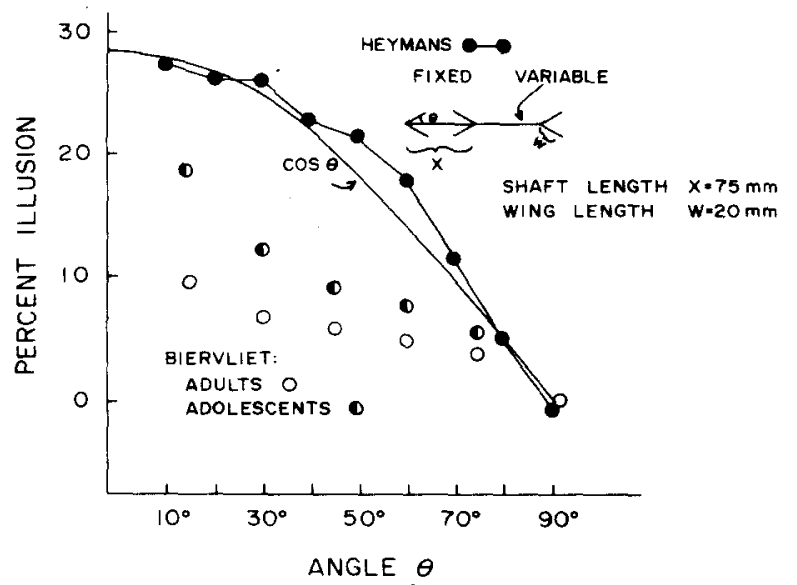

Figure 2. Percent illusion as a function of angle of wings to stem, data from Biervliet (1896) and Heymans (1896, Table 1$)$.

The magnitude of illusion as a function of angle is shown in Figure 2. The overall length of the figure with wings out is $X-2 W \cos \theta$, where $X$ is the length of the test shaft, $W$ is wing length, and $\theta$ is angle of wings to shaft. A simple confluxion theory might say that the judged length of $X, J(X)$, would lie between $X$ and $X-2 W \cos \theta$, and would therefore be $a$ function of $\cos \theta$, the function shown in Figure 2 . Somewhat comparable data collected by Biervliet (1896) are also shown.

The second main finding from Heymans' measurements is that the illusion varies as an inverted-Ushaped function of wing length, W. Figure 3 shows the magnitude of the illusion as a function of wing length in a figure with shaft length $X=75 \mathrm{~mm}$ and an angle of $30^{\circ}$. The data points are from three different experiments which agreed with one another 


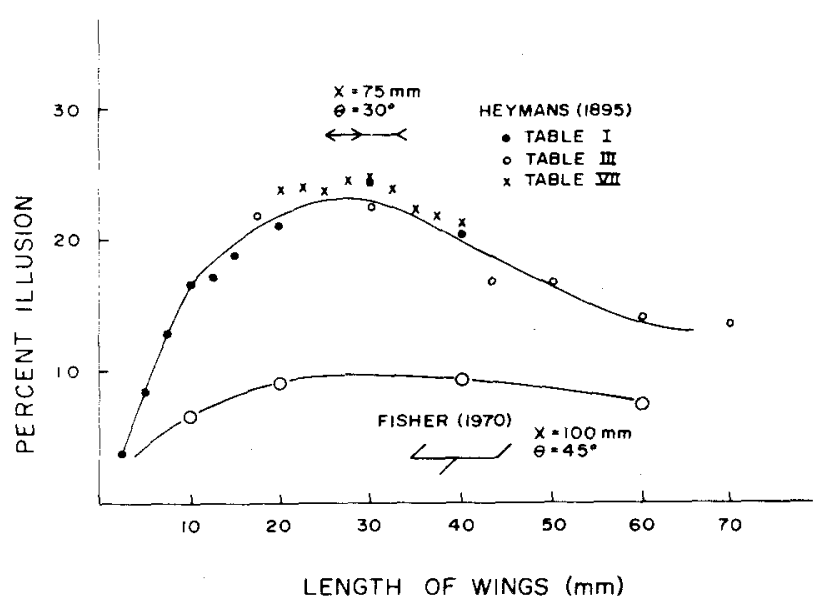

Figure 3. Percent illusion as a function of length of wings. Data from Fisher (1970) and Heymans (1896, Tables II, II, and VII).

well, and the line is a free-hand curve to indicate the general shape of the function. Notice that the maximum illusion is when the wings are approximately 25 to $30 \mathrm{~mm}$ in length, $30 \%$ to $40 \%$ of the length of the shaft. Later data from Fisher (1970), using a modified figure, are also shown. The modified figure is used in new experiments reported below.

There is some question of whether or not the wing length producing the maximum illusion is the same for all angles. Figure 4 shows the data from several of Heymans' experiments, showing that the maximum illusion with an angle of $70^{\circ}$ is produced by quite long wings, between $60 \%$ and $120 \%$ of shaft length, $\mathrm{X}$, whereas when the angle is $50^{\circ}$ the maximum is at $70 \%$ of the shaft length, at $30^{\circ}$ the maximum is at $40 \%$ of $\mathrm{X}$, and at $10^{\circ}$ the maximum is at $25 \%$ to $40 \%$ of $X$. There seems to be a consistent trend that the wing length giving rise to the maximum illusion is shorter, the more acute the angle between wings and stem. Dewar (1967) used only short wings, from $10 \%$ to $40 \%$ of the length of the test shaft, and did not find an inverted-U function within that range. His data are also shown in Figure 4.

The limitation in Heymans' and Dewars' studies, for further analysis of the illusion, is that they studied the double figure, contrasting wings in with wings out, but not measuring either effect separately. Lewis (1909) measured separate parts of the figure by presenting one-half figure (wings in or wings out) along with a variable comparison line that has no wings at all. The subject varied the comparison line to match the test shaft.

In measurements of the figure with obtuse angles (wings out), larger angles lead to larger $J(X)$ and the illusion is an inverted-U-shaped function of wing length. This does not necessarily follow from the similar observation by Heymans, because we do not know whether Heymans' data reflected changes in

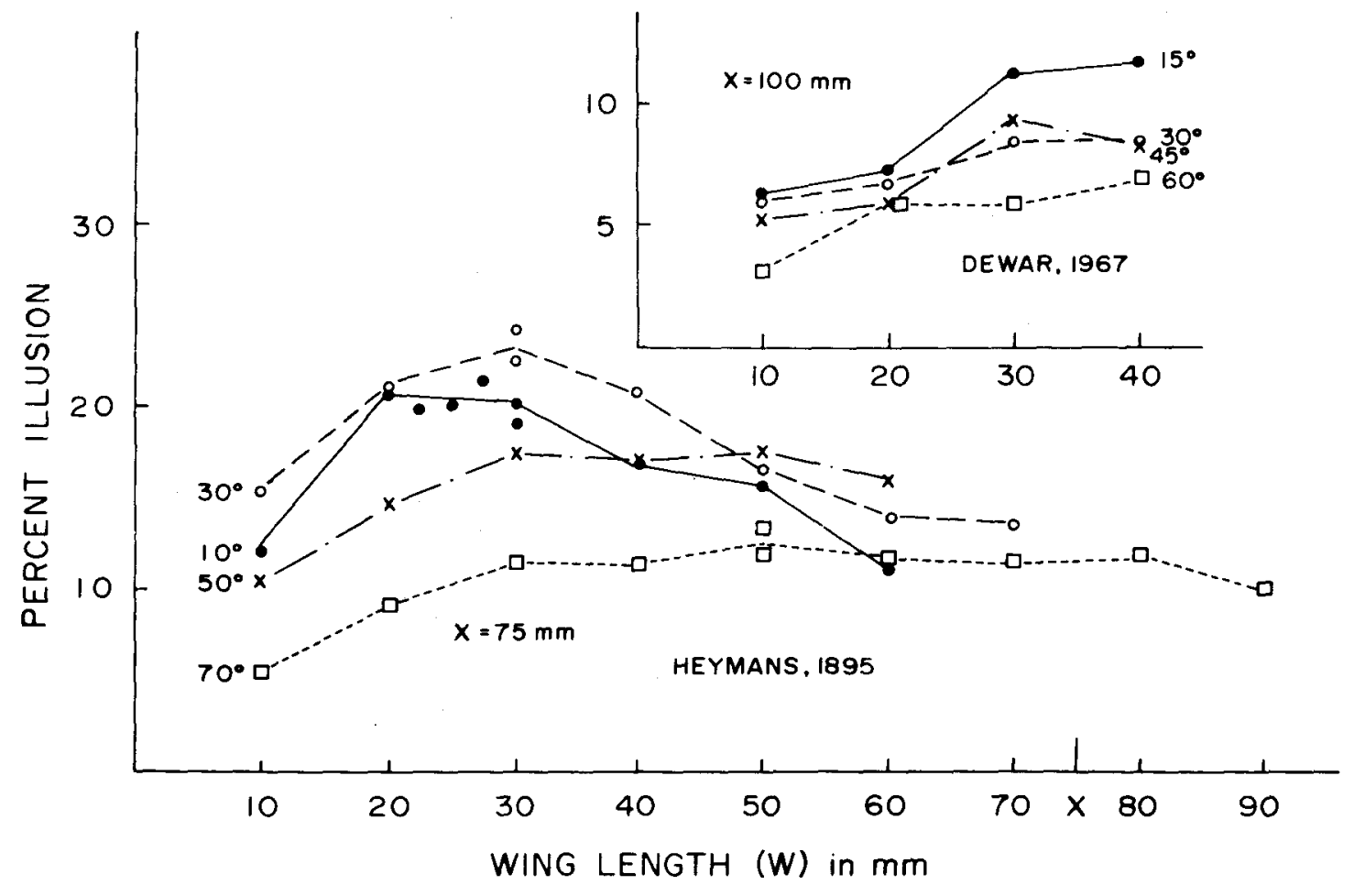

Figure 4. Percent illusions as a function of wing length for various angles. Data from Dewar (1967) and Heymans (1896, Tables II, III, IV, V, VI, VII, and VIII). Note that the maximum point of Heymans' curves is at shorter wings when the angle is more acute. 


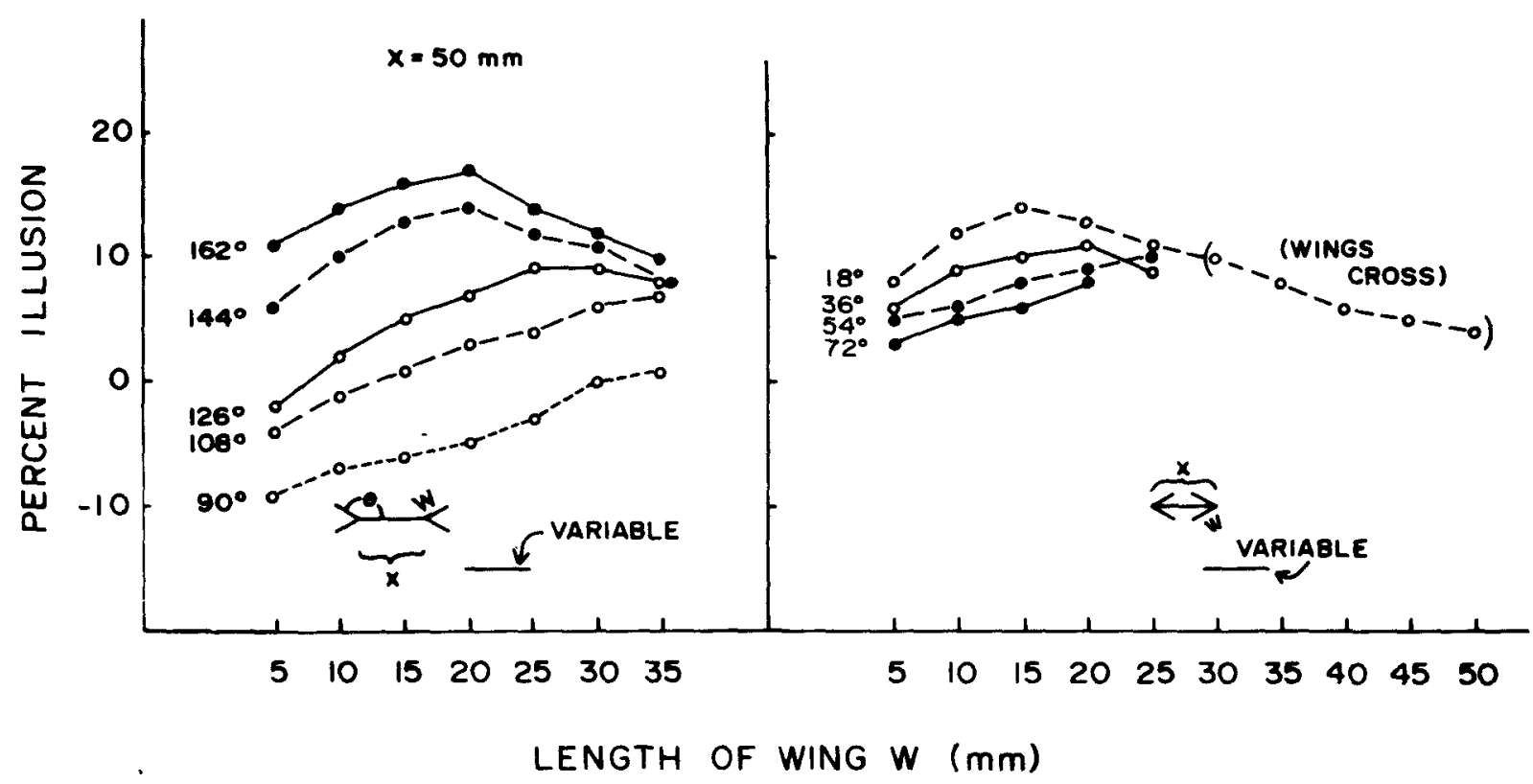

\begin{abstract}
Figure 5. Percent illusion of expansion as a function of wing length for various angles, in the single Mueller-Lyer figure with wings out (left panel), and percent illusion of contraction as a function of wing length for various angles with wings in (right panel). Data from Lewis (1909).
\end{abstract}

the length of the obtuse-angle section of the figure, the acute-angle section, or both. Lewis' data (see Figure 5) show that there is a definite change in the subfigure with an obtuse angle, and the maximum illusion relates to angle in the same way it did in Heymans' data. At angles of $108^{\circ}$ and $126^{\circ}$, the maximum occurs with relatively long wings, at least $50 \%-70 \%$ of the test shaft. When the angles are nearer $180^{\circ}$, the maximum appears with wings that are no more than $40 \%$ of X.

According to Lewis' report, when angles are acute (wings in), the illusion is larger, the smaller the angle. This result is difficult to interpret because the ordinate in Lewis' graph is unlabeled and is described as "the illusion" in the text, but never more fully described. I believe that Lewis refers to the amount of illusion in its usual direction, which would be "expansion" in the case of obtuse angles and "contraction" in the case of acute. If so, the maximum difference between wings in and wings out is a $30 \%$ illusion, as Heymans measured it. This occurs with wings $30 \%$ to $40 \%$ of $X$ and with sharp angles of $18^{\circ}$ and $162^{\circ}$, and the magnitude of illusion is comparable to Heymans' results.

More recently, Erlebacher and Sekuler (1969) studied only the inward-pointing wings, varying both angle and length of wings. They noted that, as the angle was made more acute for a given length of wings, the tips of the wings became closer and closer together. In fact, the function is that $T$, the intertip distance, is given by

$$
T=X-2 W \cos \theta,
$$

where $\theta$ is acute. Within a moderate range, Erlebacher and Sekuler found that if wing length and angle are covaried so as to keep the space $T$ between the wing tips constant, the illusion remains approximately constant.

\section{THEORY}

The Mueller-Lyer illusion has been described as the combined result of confluxion and contrast (Heymans, 1896; Lewis, 1909; Müller-Lyer, 1896a, 1896b; Piéron, 1911; Virsu, 1967), and this two-factor theory is particularly favored by those who have considered the quantitative data. The two opposing factors of confluxion and contrast can be defined at various levels of processing of the stimulus, and have different implications, depending on the level. The stimulus display results in an image that is in close geometrical correspondence with the display itself but may be distorted to produce an illusion. Then there must be some process to encode the image and extract information about lengths. The observer may extract the wrong information from the image, producing an illusion. Finally, after length information has been extracted, the subject must decide upon a judgment, usually by combining or comparing lengths. This process of judgment may result in an illusion.

On the image itself, confluxion means that two points are seen as closer together than the objective display would justify, and contrast means that they are seen as too far apart (e.g., through lateral inhibition or contour repulsion). These effects would pre- 
sumably have a fixed range of action in terms of visual angle as in lateral inhibition (Coren, 1970; Nakagawa, 1958; Wagner, 1968).

As the viewer encodes the image into lengths, he may confuse nearby extents; for example, instead of judging the length of the test shaft, he may judge the distance between the centers of gravity of figures at the ends of the test line, showing confluxion through confusion (Erlebacher \& Sekuler, 1969; Virsu, 1967). Such confusions may be associated with actual or incipient eye movements or centrations (Coren \& Hoening, 1972; Festinger, White, \& Allyn, 1968; Judd, 1905; Kaufman \& Richards, 1969; McLaughlin, DeSisto, \& Kelley, 1969; Richards \& Kaufman, 1969; Virsu, 1971). The result may be the same as if close points were seen as too close and more distant points as farther apart on the image, but if the effect results from confusion and particularly if it results from eye movements, it is more likely to be proportional to the size of the display figure than is an error of fixed retinal angle.

After extracting information about lengths, the subject in judging may let his judgment migrate toward the central tendency of lengths extracted, as in Pressey's (1967) assimilation theory, showing a form of confluxion. In this case, there need be no confusion and the various lengths involved need not be particularly near one another. In the adaptationlevel theory of illusions (Green \& Hoyle, 1964; Restle, 1971), a given length is judged in relation to an adaptation level which is the mean of lengths nearby in the field. An increase of any context length would raise the adaptation level and thereby reduce the judgment of the test stimulus, producing a form of contrast.

The main Mueller-Lyer illusion as measured by Heymans is usually attributed mainly to confluxion. The U-shaped function of wing length is attributable to a combination of confluxion (while wings are short) and contrast (having its stronger effect when wings are long). However, there is no adequate theory of why shorter wings produce confluxion and longer wings produce contrast. Essentially, it must be argued that contrast effects are stronger with longer wings, and confluxion effects increase only over a limited range, then level off or decrease with longer wings. No quantitative model with these properties has been proposed.

Furthermore, Restle (1977) has shown that the adaptation-level theory, which uses only a contrast principle and no confluxion, can itself produce an inverted-U function of a variable like wing length. Essentially, the argument is that short wings have very small weights, and the weight of the wing, i.e., its relative influence on shaft length, increases as the wing is made longer. The general field around the test shaft is large, so a bare shaft is judged quite short.
When short wings are added, they lower the adaptation level and make the shaft look somewhat longer. Further increasing wing length increases the weight of the wing, and up to a point will reduce adaptation level. When the wings are made as long as the surrounding field dimensions, then of course the shaft length appears smaller with longer wings.

These arguments suggest that understanding of the Mueller-Lyer figure will be helped by quantitative studies of figures with very short and very long wings to plot out the while function, illusion as a function of wing length.

\section{EXPERIMENT 1}

The purpose of Experiment 1 was to measure the apparent length of a test shaft with wings in and wings out, as a function of angle of wing to shaft and length of wing. While Heymans (1896) and Lewis (1909) concentrated on finding the maximum illusion and used short wings, the present study was intended to explore more extreme lengths of wing.

One difficulty with the usual form of the MuellerLyer figure, as used by Erlebacher and Sekuler (1969) for example, is that the inward-pointing wings may cross if drawn too long. Heymans (1896) tried out a version of the figure with only one wing at each end of the test shaft, one above and the other below. See also Fisher (1970) and Piéron (1911). For Heymans, this version produced an illusion almost as large as the original Mueller-Lyer figure, and it imposes no limitations on wing length. A few examples, with the relevant parameters indicated, as are shown in Figure 6.

\section{Method}

Subjects. Sixteen students from a spring semester psychology course (1976) at Indiana University served as part of the course requirement.

Apparatus. Stimuli were displayed at $500 \mathrm{~mm}$ distance on a VR-14 point-plot oscilloscope (Digital Electronic) controlled by an IBM 1800 laboratory computer. Stimuli were located in a $140 \times 140 \mathrm{~mm}$ area and appeared without perceptible flicker. The subject had a response box with 15 buttons arranged in a row. The center button (No. 8) and the extreme right-hand button (No. 15) were modified with masking tape so as to be distinguishable by touch from the others. Any button to the left
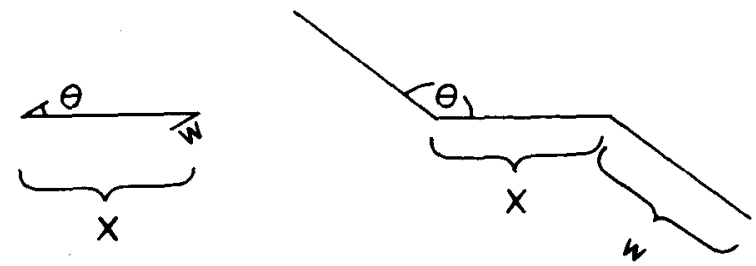

Figure 6. Sample displays for the modified Mueller-Lyer figure used in most of our new experiments. Each such figure is presented along with a variable comparison line, which is matched to the apparent length of the horizontal test shaft. Parameters of the display are indicated. 
of the center button, if pressed, caused the variable comparison line to be shortened, the amount of the shortening being proportional to how far the button was to the left of center. Similarly, buttons to the right caused the variable line to be lengthened. The button at the extreme right, marked with masking tape, caused the subject's present setting to be recorded as his response. The stimulus field was then extinguished for $2 \mathrm{sec}$, following which the next display was shown.

All presentation of stimuli, changes of comparison line, recording of responses, and timing were performed automatically by the computer.

Materials. Each display consisted of a standard shaft of length $X$, either 19.60 or $23.10 \mathrm{~mm}$, centered $17.5 \mathrm{~mm}$ to the left of center of the screen and half way between the top and bottom. At the left end of this shaft was appended a wing pointing upward at an angle of $20^{\circ}, 50^{\circ}, 90^{\circ}, 130^{\circ}$, or $160^{\circ}$, and another wing from the right end pointing downward and forming the same angle to the shaft. The two wings in any display were equal in length, $W$, of $1.05,2.10,3.15,4.20,8.75$, or $42.00 \mathrm{~mm}$. The computer programs drew lines by plotting points $.175 \mathrm{~mm}$ apart, producing an apparently continuous line approximately $.30 \mathrm{~mm}$ wide. At the point of intersection of line and wing, care was taken not to plot doubly, which would have produced a distinguishably bright point.

In each display, there was also a variable comparison stimulus of starting length, $\mathrm{Y}=28.00 \mathrm{~mm}$ centered $52.50 \mathrm{~mm}$ to the right of the center of the screen and $35.00 \mathrm{~mm}$ above the midline. In this position, the comparison segment never was close to any part of the shaft or wings of the standard.

The two shaft lengths, $\mathrm{X}$, five angles, $\theta$, and six wing lengths, $\mathrm{W}$, were combined factorially to yield 60 different displays.

Procedure. Subjects were instructed on how to match the variable line, $Y$, to the test shaft, $X$. On each trial, one of the stimulus displays, in randomly permuted order, was presented, and the subject was free to make any adjustments he desired until the variable line, $Y$, appeared equal to $X$. The subject then pressed the extreme right-hand button to record his response and to obtain the next display. The 60 displays were shown twice in two successive random permutations, but only the second replication is reported, the first being considered practice. Each subject was instructed and tested individually. A session, including instruction, practice, and test, consumed approximately $45 \mathrm{~min}$.

Let $X$ by the physical length of the test shaft and $Y$ the length of the variable line matched to it. Let $Y_{0}$ be the length of the variable matched to a control test shaft of length $X$ having no wings. Then the proportional illusion is:

$$
\mathrm{I}=\frac{\mathrm{Y}-\mathrm{Y}_{\mathrm{o}}}{\mathrm{X}}
$$

This definition could not be applied with confidence to the data from existing experiments or to Experiments 1 and 6 which did not have control lines without wings. When no control line is used, $Y_{0}$ is not known, and we used a "raw illusion" defined as

$$
\mathbf{I}_{R}=\frac{Y-X}{X}
$$

\section{Results}

The data shown in Figure 7 are comparable to those of Lewis (1909). Our wings-out figures show an inverted- $U$ function of $W$ with a maximum at about $30 \%$ to $50 \%$ of the shaft length. Like Lewis, we found that the maximum lay at a shorter $W$ (about $20 \%$ of shaft length) when the angle was very obtuse, $160^{\circ}$, and somewhere between $20 \%$ and $60 \%$ when the angle was $130^{\circ}$. Our selection of wing lengths did not locate the maximum exactly, but our data agree

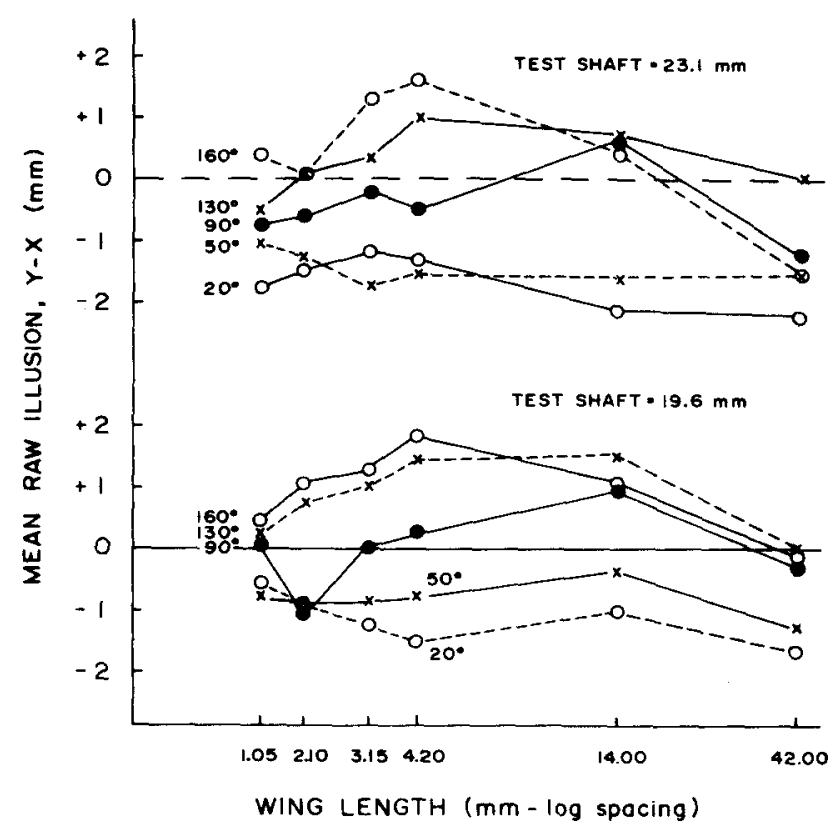

Figure 7. Mean raw illusion in millimeters as a function of wing length for various angles, with two different lengths of test shaft. Note the contraction effect with $\theta=160^{\circ}$ and long wings.

with Lewis' within our precision of measurement. In addition, we observed that with very long wings and an obtuse angle, the curve drops so far that there is a substantial negative illusion.

Our data on the $90^{\circ}$ display agree generally with that of Lewis in that the illusion follows a positive trend up to a wing length somewhat less than the shaft length, $X$. However, we found that with a very long wing $(42 \mathrm{~mm})$, the illusion turns negative.

The two acute angles (wings in) both produced negative illusions, and in general the $20^{\circ}$ angle produced a more negative illusion than the $50^{\circ}$ angle. Neither figure showed much sensitivity to wing length.

Finally, Figure 7 shows a slight apparent central tendency, in that subjects seemed to underestimate the longer test shaft of $23.1 \mathrm{~mm}$ relative to the shorter of $19.6 \mathrm{~mm}$. Experiment 1 did not use a control condition in which the test shaft, $X$, was presented without any wings, and therefore it is unwise to draw firm conclusions as to the absolute direction or magnitude of the illusions found.

\section{Discussion}

Whereas the earlier quantitative measurements of Heymans and Lewis concentrated on finding the maximum illusion, the present study used a wider range of wing lengths. Our results show that with wings out the illusion is an inverted-U function which extends over a wide range of wing lengths, from $1 / 20$ th to over twice the shaft length. The function with $90^{\circ}$ wings is not flat, but shows an inverted-U 
function also, but with its maximum at a relatively long wing length. The figure with wings in (acute angles) shows a negative illusion that is not sensitive to wing length.

Because our figure had only a single wing at each end, there are limits on the possible interpretations of the data. The hypothesis of Erlebacher and Sekuler (1969) that the illusion depends upon the distance between the tips of the wings cannot be applied to the present figure. Having only one wing above the test shaft, our display does not define the ErlebacherSekuler distance. However, our figure also appears insensitive to wing length, a finding that might fit with the Erlebacher-Sekuler hypothesis.

The inverted- $U$ function of wing length, in the case of the wings-out figure, can be explained by a mixture of confluxion (with short wings) and contrast (with very long wings). However, we also found what appears to be an inverted-U function of wing length when the wings are at $90^{\circ}$, and this figure gives little opportunity for application of the confluxion part of the theory, since this figure does not increase in overall length as the wing is lengthened. This suggests that at least one component of the inverted- $U$ function is independent of overall length of the figure, and therefore of confluxion arising from either lateral spread on the image or of confusion in extracting length information. '

\section{EXPERIMENT 2}

The figure with $90^{\circ}$ wings was of particular interest in Experiment 1 because it led to an inverted- $U$ function which could not be attributed to confluxion in the image or confusion in coding the image to lengths. From our theoretical position, we can therefore conclude that the inverted-U function at $90^{\circ}$ arises from confluxion or contrast at the level of judgment, from combining or comparing lengths. Experiment 2 was designed to submit this $90^{\circ}$ display to a closer analysis in an attempt to verify if the functional relationship between $J(X)$ and $W$ was in fact an inverted $U$, and if so, where the maximum of this function was located. We used an $\mathrm{H}$-shaped figure in this experiment.

\section{Method}

Subjects and Procedure. Nine new subjects from summer school classes (1976) at Indiana University were given seven replications of the stimulus set in seven random permutations. The last six replications are here reported as data.

Materials. Test shafts, $X$, were always $7.00 \mathrm{~mm}$ in length, centered $21.00 \mathrm{~mm}$ to the left of center of the screen and halfway between top and bottom. The comparison line, Y, extended from $56.00 \mathrm{~mm}$ to the right of center of the screen rightward either 12.95 or $15.00 \mathrm{~mm}$, and then was adjusted by the subject, whose adjustment responses added or removed segments from the right end of the comparison line. The main experimental variable was the length of the wings, which extended equally above and below each end of the test shaft in an $H$ shape and were of total length $0.00,1.75,3.50,7.00,14.00,28.00$, or $56.00 \mathrm{~mm}$.

\section{Results}

If illusory effects occurred at the level of image or coding of image to length and none at the level of judgment, then the lengths of these $90^{\circ}$ wings would have no effect on $J(X)$. The presence of judgmental effects was shown by the significant effect of wings, $F(7,768)=6.66, p<.001$.

Figure 8 shows that the illusion as a function of wing length describes an inverted- $U$ function, having a maximum in the region of $7.00 \mathrm{~mm}$, where wing length equals test shaft length.

The illusion is predominantly positive in that $\mathrm{J}(\mathrm{X})$ with wings is larger than $J(X)$ without wings, and is also larger than $\mathrm{X}$ itself in millimeters. If the wings are sufficiently long, however, eight times as long as the test shaft, the illusion turns slightly negative.

\section{Discussion}

The inverted- $U$ function can be explained by either of two judgmental theories, the assimilation approach (Pressey \& Murray, 1976) or adaptation-level theory (Restle, 1977).

In the Pressey-Murray model, the illusion is proportional to the wing length times a weighting given by $1-\left(D^{\prime} w / D^{\prime}\right)$, where $D^{\prime} w$ is the distance from the end of the shaft to the end of the wing, i.e., our $W$, and $D^{\prime} P$ is the distance from the end of the shaft to "the periphery," a relatively large distance to be estimated from the data. From this formulation, illusion, $I$, is given by

$$
I=W\left(1-\frac{W}{D^{\prime} P}\right)=W-\left(1 / D^{\prime}{ }_{P}\right) W^{2}
$$

a quadratic equation in $\mathrm{W}$ which first increases with

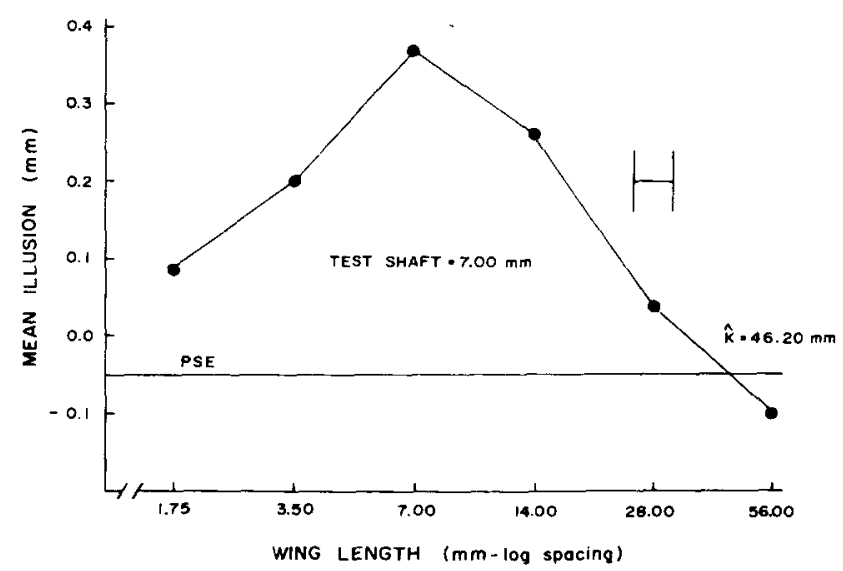

Figure 8. Mean raw illusion, as a function of length of wings in an $\mathrm{H}$-shaped figure, $\theta=90^{\circ}$. 
$W$, until $W=1 / 2 D_{p}^{\prime}$, then decreases. This is shown by

$$
\mathrm{dI} / \mathrm{dW}=1-2 \mathrm{~W} / \mathrm{D}^{\prime} \mathrm{P},
$$

which is positive, meaning that the function is increasing, if $W$ is less than $1 / 2 D^{\prime} P$ and negative when $\mathrm{W}$ is greater than that value. Thus, according to the Pressey-Murray theory, the illusion will be an inverted$\mathrm{U}$ function, quadratic in nature, with one maximum. Our data show that the maximum illusion occurs when $\mathrm{W}=\mathrm{X}$, which according to the Pressey-Murray formulation must be an accident.

Restle (1977) supposed that the weight of the wing in the adaptation level would depend upon the magnitude of $\mathrm{W}$ itself. In the basic formulas,

$$
\mathrm{J}(\mathrm{X})=\mathrm{X} / \mathrm{A}
$$

where

$$
A=\left(K^{k} W^{\beta}\right)^{1 / k+\beta}
$$

so that

$\log \mathrm{J}(\mathrm{X})=\log \mathrm{X}-\frac{\mathrm{k}}{\mathrm{k}+\beta} \log \mathrm{K}-\frac{\beta}{\mathrm{k}+\beta} \log \mathrm{W}$.

The judgment of the variable comparison line is given by the same equations (disregarding possible "crosstalk" between standard and comparison) by

$$
\mathrm{J}(\mathrm{Y})=\mathrm{Y} / \mathrm{A}_{\mathrm{Y}}=\mathrm{Y} / \mathrm{K}^{\prime},
$$

where $\mathrm{K}^{\prime}$ is the constant field around the variable comparison line. Thus,

$$
\log \mathrm{J}(\mathrm{Y})=\log \mathrm{Y}-\log \mathrm{K}^{\prime} .
$$

When the subject has made his adjustment, the judgment of $Y$ is equal to the judgment of $X$, so that

$$
\mathbf{J}(\mathbf{Y})=\mathbf{J}(\mathbf{X})
$$

and

$\log Y-\log \mathrm{K}^{\prime}=\log \mathrm{X}-\frac{\mathrm{k}}{\mathrm{k}+\beta} \log \mathrm{K}-\frac{\beta}{\mathrm{k}+\beta} \log \mathrm{W}$.

Assuming that the constant factors are the same on both sides of the field, i.e., that $K^{\prime}=K$, then

$$
\log \left(\frac{Y}{X}\right)=\frac{\beta}{k+\beta}(\log K-\log W)
$$

To explain the inverted- $U$ function, we assume that $\beta$ is a function of wing length, $W$, with these properties: if $\beta=f(W)$, then a wing of 0 length has 0 weight, that is,

$$
f(0)=0
$$

and the weight is never negative, so that

$$
\mathrm{f}(\mathrm{W}) \geqslant 0 \text { for all } \mathrm{W}>0 .
$$

However, if $\mathbf{W}=\mathrm{K}$, then $\log \mathrm{K}-\log \mathrm{W}=0$, whence the $\log$ illusion is also 0 . Also, if $W=0$, the $\log$ illusion is 0 , since

$$
\lim _{W \rightarrow 0} \frac{f(W)}{k+f(W)}[\log K-\log W]
$$

is zero provided $f(0)=0$, as is shown by employing a series expansion of the logarithm.

At any value of $W$ between 0 and $K$, the illusion is positive. The reason is that the adaptation level is a weighted average of $W$ and $K$, and therefore lies below $K$, hence $J(X)$ must lie above $X / K$. This, however, means that $\mathrm{J}(\mathrm{X})$ is above $\mathrm{J}(\mathrm{Y})$ if $\mathrm{Y}=\mathrm{X}$, and therefore the illusion must be positive. Since it is positive in the interval $0<\mathrm{W}<\mathrm{K}$ and zero at both ends, the function must have a maximum in between. We have not proved that the function must be a simple inverted $\mathrm{U}$, but any other function would be produced by making $\beta$ a complicated function of $W$, for which there is no empirical or theoretical justification.

Again, however, as in the Pressey-Murray theory, there is no obvious reason why the maximum should lie at $W=X$, from the above equation. Restle (1977) did accept Sarris' (1976) hypothesis that $\beta$ is actually a function of $W / X$ if $W$ is less than $X$, and of $X / W$ if $W$ is greater than $X$. This would make $\beta$ have a maximum at $W=X$, though this does not mean that the illusion would also be a maximum at this value.

According to this formulation, the illusion is at zero when $\mathbf{W}=\mathbf{K}$, and this permits an estimate of $K$ in millimeters. Interpolation from Figure 8 suggests that the estimate is near $K=46.20 \mathrm{~mm}$. In other experiments in this apparatus, using boxes instead of an $\mathrm{H}$-shaped figure and using a rating-scale response rather than method of adjustment, Dumais (discussed by Restle, 1977) found estimates of $K$ at 42.00 and at $49.00 \mathrm{~mm}$ in two experiments.

\section{EXPERIMENT 3}

The results of Experiments 1 and 2 leave us with a question regarding the wing length that produces the maximum overestimation of $X$. It seems that, when 
the angle is very obtuse, the maximum lies at $\mathbf{W}=$ $.25 \mathrm{X}$ or $\mathrm{W}=.50 \mathrm{X}$, but when the angle is $90^{\circ}$, the maximum is at $W=X$. This statement of the locations of the maxima is merely a summary indication of the fact that the function relating $J(X)$ to $W$ is different depending upon the angle $\theta$. Since the $90^{\circ}$ figure is affected only by judgmental factors and the figures with obtuse angles may be affected also at lower levels of processing, the difference in shape of the function relating $J(X)$ to $W$ is theoretically crucial. The data from the first two experiments are compatible with the idea that a $90^{\circ}$ figure is special. However, these earlier experiments failed to explore any angles between $90^{\circ}$ and $130^{\circ}$, and did not obtain very accurate locations of the maxima. Experiment 3 was intended to fill this gap and determine whether there is a gradual change in the shape of the function with small changes in angle $\theta$, or whether $90^{\circ}$ is special.

\section{Method}

Subjects. Ten new subjects from the summer-school pool were used.

Apparatus and Procedure. The same apparatus and procedure were used. Three replications of the stimulus set were shown, of which the second and third are reported below as data.

Materials. Test shafts were $7.00 \mathrm{~mm}$ long, and were laid out as in Experiment 1 with one wing at each end of the shaft, one above and the other below. Wings were of length $0.00,0.84,1.68,3.36$, 7.00 , or $14.00 \mathrm{~mm}$, and were affixed at angles of $97^{\circ}, 104^{\circ}, 113^{\circ}$, $119^{\circ}$, or $129^{\circ}$. The variable comparison line was started either $1.12 \mathrm{~mm}$ longer or $1.12 \mathrm{~mm}$ shorter than the test shaft.

\section{Results}

The main results, shown in Figure 9, are that all

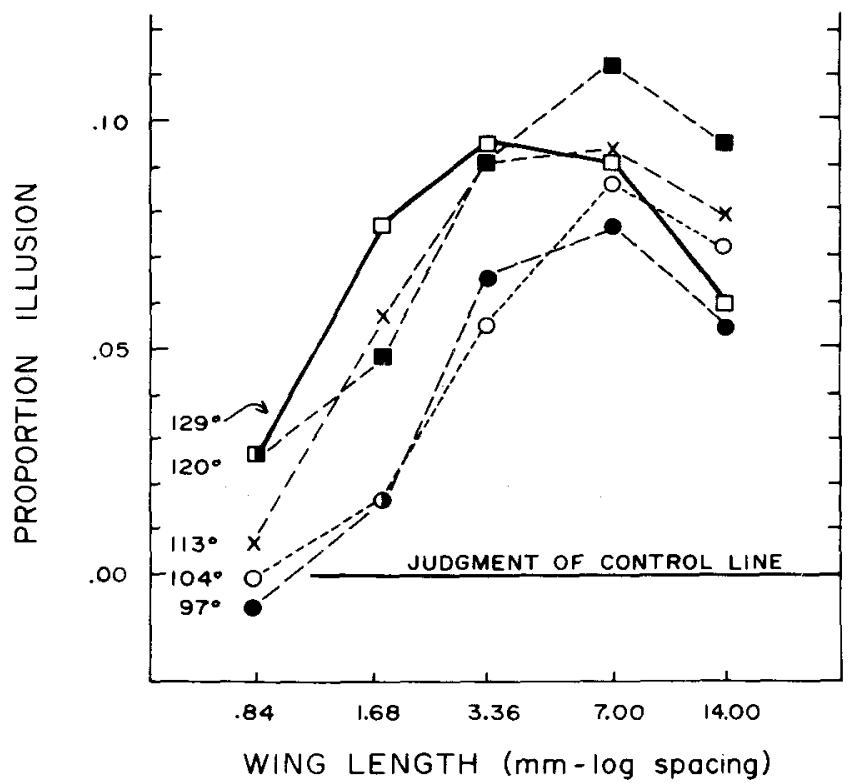

Figure 9. Proportion of illusion as a function of wing length for angles between $90^{\circ}$ and $129^{\circ}$. Notice the gradual change in curves, with the maximum shifting downward with respect to $W$ as the angle becomes more obtuse. functions of $\mathrm{W}$ are inverted-U shaped. At $97^{\circ}, 104^{\circ}$, and $120^{\circ}$, the observed maximum is at $\mathrm{W}=7.00$, equal to the length of the test shaft, but at $113^{\circ}$, the maximum might be interpolated to be between 3.36 and $7.00 \mathrm{~mm}$, and at the most obtuse angle, $129^{\circ}$, the maximum is at $3.36 \mathrm{~mm}$, about half the test shaft. These data display no sharp discontinuity, but show a general trend in that the maximum of $J(X)$ is at $\mathrm{W}=\mathrm{X}$ for angles near $90^{\circ}$, and at smaller values of $\mathrm{W}$ when the angle is relatively obtuse.

\section{EXPERIMENT 4}

The results of Experiments 1-3 provide various insights into the relation of wing angle and wing length to the judgment of the test shaft, but do not provide a comprehensive picture of the total functional relationship. Experiment 4 was designed to complete this survey.

\section{Method}

Subjects. Fifteen new subjects from the summer-school pool were used.

Procedure. Eight stimuli with various values of $\mathrm{W}$ and $\theta$ were chosen for practice. Each subject was individually instructed through these practice trials, and then made a single setting on each of 144 displays presented in a separate random permutation for each subject.

Materials. In the main design, test shafts were $7.00 \mathrm{~mm}$, and wings were drawn at an angle of $14^{\circ}, 30^{\circ}, 45^{\circ}, 60^{\circ}, 76^{\circ}, 90^{\circ}$, $104^{\circ}, 120^{\circ}, 135^{\circ}, 150^{\circ}$, or $166^{\circ}$, making 11 angles. The wings were of length $1.68,3.36,7.00,14.00,28.00$, or $56.00 \mathrm{~mm}$. A subsidiary control set of test stimuli had shafts of length $5.60,6.30,7.00$, 7.70 , or $8.40 \mathrm{~mm}$ with no wings.

\section{Results}

The main results are shown in Figure 10. In the top half, figures with outward wings, all the functions of $\mathrm{W}$ are inverted-U shaped. At $90^{\circ}, 104^{\circ}$, and $120^{\circ}$, the maximum is at $\mathrm{W}=.50 \mathrm{X}$. At the very obtuse angle of $166^{\circ}$, the maximum is at $\mathrm{W}=.25 \mathrm{X}$. These data clearly reveal a smooth transition between the function at $90^{\circ}$ and the extreme function with an obtuse angle. Also, Figure 10 makes it obvious that when the angle is very large and the wings very long, the function turns sharply downward so that, with wings of 28.00 and $56.00 \mathrm{~mm}$ and an angle of $166^{\circ}$, the illusion is actually negative.

The lower half of Figure 10 reveals that, as the angles become more acute, from $90^{\circ}$ to $14^{\circ}$, the overall illusion becomes progressively more negative, as in Experiment 1. It is interesting to note that every one of these functions with inward-pointing wings also shows a maximum of $J(X)$ (which would be a minimum of the shrinkage illusion) at $\mathrm{W}=\mathrm{X}$, just as in the $90^{\circ}$ figure.

Figure 10 is drawn relative to the point of subjective equality found by setting variable $\mathrm{Y}$ equal to a control test shaft, $X$, with no wings. Responses to these control lines were essentially veridical. 


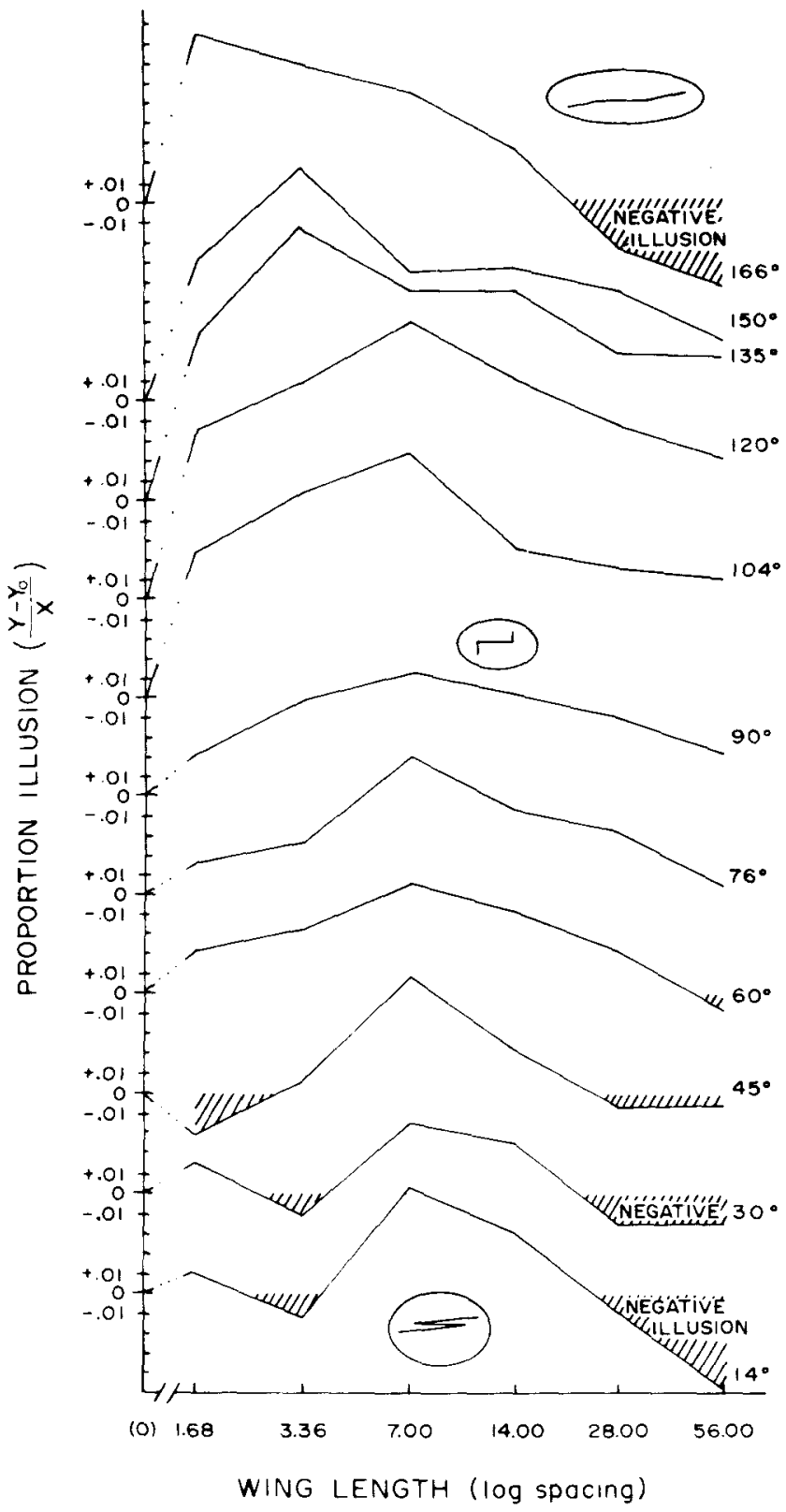

Figure 10. Proportion of illusion as a function of wing length for angles from $166^{\circ}$ to $14^{\circ}$. Notice that for all acute angles and up to $120^{\circ}$, the curve has a maximum, at $W=X$, of $7.00 \mathrm{~mm}$. With more obtuse angles, the maximum steadily moves to lower values of $W$. The overall effect of angles is monotonic except over $120^{\circ}$.

\section{Discussion}

Confluxion is evident, in Figure 10, in the fact that the illusion is positive when the angle is obtuse and negligible or negative with the angle acute. Contrast is probably represented by the inverted- $U$ function imposed on this general confluxion trend.

With only one wing at each end of the test shaft, our figure does not have the kind of wing-to-wing lengths used, theoretically, by Erlebacher and Sekuler (1969) and by Pressey (1970). However, Pressey (1970), in analysis of a related figure, has suggested the distance from one end of the test shaft to the wing at the other end as a possible factor. This distance to any point on the wing a distance $y$ from the end of the shaft is given by

$$
L^{2} y=X^{2}+y^{2}-2 X y \cos \theta .
$$

The mean value of $\mathrm{L}^{2}$ is then

$$
\begin{aligned}
L^{2} & =\frac{1}{W} \int_{0}^{W}\left(X^{2}+y^{2}-2 X y \cos \theta\right) d y \\
& =X^{2}-X W \cos \theta+W^{2} / 3 .
\end{aligned}
$$

Wing length, $\mathbf{W}$, is also involved in contrast, but $\cos \theta$ is not in the formulation we have used. This leads to the expectation of a "cosine law" as formulated by Heymans, except that in the new formulation the judgment should be a function of

$$
\sqrt{\alpha-\beta \cos \theta} \text {. }
$$

Clearly this is not the whole story, for the illusion decreases and even turns negative when $\theta$ and $W$ are both large. In such figures, though, one end of the test shaft and the wing at the other end do not clearly enclose a space-the impression is more of a bent line. It is possible that this form of assimilation theory, with suitable constraints to take account of changes in configuration, may successfully account for these data.

\section{EXPERIMENT 5}

In Experiments 1-4, we have repeatedly found a maximum in the inverted- $U$ function located near $\mathrm{W}=\mathrm{X}$, when the angle is either acute, $90^{\circ}$, or not greater than about $120^{\circ}$. However, none of the above experiments is conclusive, because we have not varied $\mathrm{X}$ over a wide range or obtained accurate estimates of the maximum illusion. The results above might well be a coincidence-that we happened to use shaft lengths, $X$, of about $7.00 \mathrm{~mm}$ and that the maximum illusion is obtained with a wing length of about $7.00 \mathrm{~mm}$, at our viewing distance. Experiment 5 was designed to decide whether the maximum actually follows $X$ when $X$ is varied over a range from 3.50 to $14.00 \mathrm{~mm}$.

\section{Method}

Subjects. Twenty-six subjects from introductory psychology classes in the fall semester of 1976 were used.

Procedure. Fifteen stimuli were chosen, having long and short wings at acute, right, and obtuse angles and with three different 
shaft lengths, for practice. Each subject was individually instructed through these practice stimuli. After practice, the subject made a single setting on each of 105 stimuli as described below. The test stimuli were presented in random permutation, different for each subject.

Materials. In the main design, test shafts were $3.50,7.00$, or $14.00 \mathrm{~mm}$ in length, and wings were drawn at angles of $14^{\circ}$, $90^{\circ}$, or $166^{\circ}$ to that shaft, of lengths $1.25,1.75,2.50,3.50$, $5.00,7.00,10.00,14.00,20.00$, and $28.00 \mathrm{~mm}$. The variable comparison line, $Y$, was started at a random value from $1.96 \mathrm{~mm}$ shorter than test shaft, $X$, to $1.96 \mathrm{~mm}$ longer than $X$, in a uniform distribution of starting places. Starting positions were randomly chosen but not factorially combined with other stimulus parameters. A subsidiary control set of test stimuli had shafts of length $3.50,7.00$, or $14.00 \mathrm{~mm}$ with no wings. Five replications of these control stimuli were interspersed with the main design stimuli.

\section{Results}

The graphs in Figure 11 show the mean illusion as a function of wing length. The three sections correspond to wings out, up, and in. Within each section are the three curves corresponding to short $(3.5 \mathrm{~mm})$, medium $(7.0 \mathrm{~mm})$, and long $(14.00 \mathrm{~mm})$ test shafts. The dependent variable, proportional illusion, was calculated by taking the raw setting of the comparison length, $Y$, subtracting the value $Y_{0}$ set to match the control line of length $X$ with no wings, and then dividing by the shaft length, $X$. If illusions are strictly proportional to shaft length $X$, the three curves within a section would be approximately alike, and the levels are in fact comparable.

However, previous data had suggested that the effect of a given wing length, $W$, might be proportional to shaft length, $X$. In Figure 11, this would mean that the curves for the three values of $X$ would be displaced to the right. In this regard, the maximum point of the curve for $X=3.5 \mathrm{~mm}$ lies at $5.0 \mathrm{~mm}$ when the angle is either acute or at $90^{\circ}$. When $X=$ $7.0 \mathrm{~mm}$, the maximum is at $10 \mathrm{~mm}$ when the angle is acute, and at 3.5 or $7.0 \mathrm{~mm}$ when the angle is $90^{\circ}$. When $X=14.0 \mathrm{~mm}$, the maxima are at 14.0 or $10.0 \mathrm{~mm}$. The curves are too flat to yield exact locations of the maxima, but the maxima generally are near $W=X$. When the angle is obtuse $\left(\theta=166^{\circ}\right)$, as found earlier, the maximum is at a shorter wing length. For $X=3.5$, the maximum is at $1.25 \mathrm{~mm}$. For $X=7.0$, the maximum is at $3.5 \mathrm{~mm}$. At $X=$ 14.0, maxima lie at 3.5 and $7.0 \mathrm{~mm}$. Again the maxima vary with the value of $X$.

A considerable constant error was found in matching variable line $Y$ to $X_{0}$, a test shaft without any wings. At $X=3.5 \mathrm{~mm}$, the error was $-1.4 \%$. At $X=7.0 \mathrm{~mm}$, the error was $-4.5 \%$. At $X=14$, the error was $-5.9 \%$. This suggests a central tendency effect as would be predicted by assimilation theory, in that longer lines are more drastically underestimated. The general underestimate suggests that the larger total configurations involving test shafts and wings have set up a higher AL than the variable lines $\mathrm{Y}$ alone, producing a tendency to match a short $\mathrm{Y}$ with a longer $X_{o}$. The effect is quite large when one

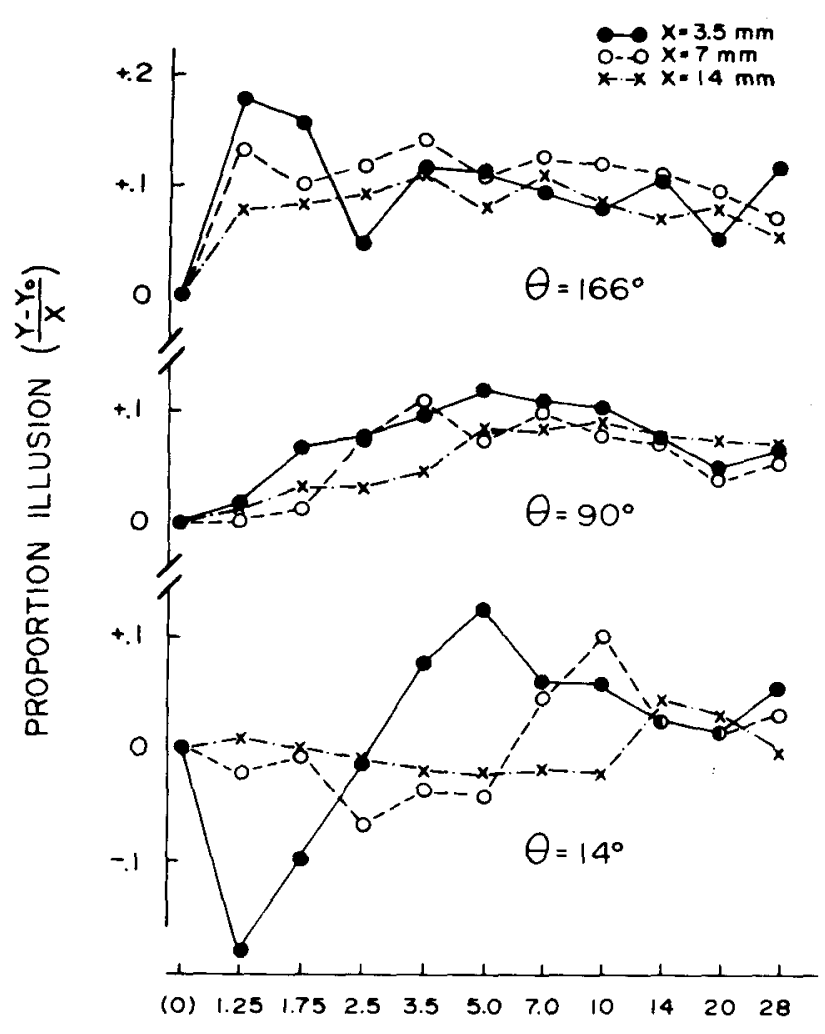

WING LENGTH ( $\mathrm{mm}-\log$ spacing)

Figure 11. Mean illusion as a function of wing length for three values of shaft length, $X$, separately for obtuse, right, and acute angles. Approximate coincidence of the three curves for each angle means that the illusion is approximately proportional to shaft length, $X$. However, note that the maximum of each function varies with shaft length, with a tendency for the maximum to lie near $\mathbf{W}=\mathbf{1 . 4 X}$.

realizes that the subject is merely matching the lengths of otherwise identical line segments, a task usually involving no constant and very little variable error.

\section{Discussion}

The results of Experiment 5 support the contention that these illusory effects are roughly proportional to the shaft length, $X$. This validates measuring illusions as proportions of $\mathrm{X}$, and gives meaning to descriptions of wing length relative to $X$.

There is also a substantive conclusion to draw. If these illusions occurred as distortions of the image, their magnitude would probably be independent of $X$, so the result suggests that the illusion arises at a later point in processing. A simpler way of testing the "retinal angle" hypothesis is to leave the figure unchanged and vary viewing distance. This changes all dimensions, including the thickness of lines, by equal proportions, but also permits changes in accommodation, convergence, etc., which in turn may engage "constancy mechanisms." The present experiment avoids distance cues, but at a price. At $X=3.5 \mathrm{~mm}$ 
and $\mathrm{W}=1.25 \mathrm{~mm}$, for example, the line thickness of approximately $0.30 \mathrm{~mm}$ is appreciable, and the shaft and wings overlay for an appreciable fraction of their length. Figure 11 shows that responses are relatively unstable with short shaft and short wings pointing in.

One finding in all experiments reported above is that we find a positive illusion with wings pointed in. A simple explanation might be that when very long wings are folded in, the total length of the figure is greater than $\mathrm{X}$, and judgments might depend on this total length. However, Figure 11 shows that the positive illusion is found when $\mathrm{W}=\mathrm{X}$, or even when $\mathrm{W}$ is slightly shorter than $X$, and it reaches a maximum when the wing is only slightly longer than $X$.

\section{EXPERIMENT 6}

Taken together, Experiments 1-5 show that the part of the display right near the tips of the test shaft has an important influence on the illusion, though the rest of the wing is also influential. One hypothesis is that confluxion effects occur only near the tips of the shaft, and other effects are all of contrast. This hypothesis does not become concrete until we determine the size of the region to be called "near the tips."

It is known that separating wings from shaft by a gap produces reduced, even reversed, illusion (Fellows, 1968), but this process makes several changes in the overall dimensions of the figures, and leaves an open gap which could lead to changes in figure-ground organization. It is also possible to separate the wing from the tip of the test shaft by inserting a vertical spacing line. Being vertical (at $90^{\circ}$ to the test shaft), this spacing line should itself have very little confluxion effect, and of course its effect must be essentially the same whether the wing at the end of the spacer points in or out. If the spacer is very short, then a wing pointing in should shorten, a wing out should increase the apparent length of $X$. As the spacer gets longer, this wings-in vs. wings-out difference should decrease, assuming that only the region near the tips of the shaft is important. The data, showing the effect of various spacers, should thereby delineate the region "near the wing tip."

\section{Method}

Subjects and Procedure. Ten new subjects from the summerschool pool served as subjects. Procedure and apparatus were essentially as in the above experiments. The subjects were shown seven random permutations each of 24 displays, and the last five replications are reported as data.

Materials. Each display consisted of a test shaft of 10.50 or $24.50 \mathrm{~mm}$, at each end of which was appended a short "spacer," a vertical line of length $0.00,0.88,17.5,2.63,3.50$, or $7.00 \mathrm{~mm}$. This line pointed up from the left end of the test shaft, down from the right end. At the end of the spacer was a wing of length $17.5 \mathrm{~mm}$ at an angle (relative to the shaft itself) of either $20^{\circ}$ or $160^{\circ}$.

\section{Results}

We expect to find the usual Mueller-Lyer illusion, that the shaft with wings in will appear shorter than the shaft with wings out, when the spacer is absent or very short. The decrease of this illusion, as the spacer gets longer, is a possible measure of the area within which wings are effective.

Figure 12 shows that when the test shaft is long, at $24.50 \mathrm{~mm}$, the experimental result agrees with the hypothesis that propinquity is important. There is a substantial $\mathbf{( 8 \% )}$ ) Mueller-Lyer illusion when the spacers are either 0 or $0.88 \mathrm{~mm}$, and this illusion becomes steadily smaller as the spacer is lengthened until the illusion disappears with a spacer of $3.50 \mathrm{~mm}$. With a shorter test shaft, $10.5 \mathrm{~mm}$, there is the usual Mueller-Lyer illusion with no spacer, but even the shortest spacer of $0.88 \mathrm{~mm}$ is enough to remove and slightly reverse the illusion, and with any longer spacer there is a reversed Mueller-Lyer illusion of approximately $5 \%$; the test shaft with wings out looks smaller than the test shaft with wings in. The angle of the wings appears to have an effect when separated from the test shaft by a small distance; our estimates would be that the effect disappears at about $3.50 \mathrm{~mm}$ when the shaft is $24.5 \mathrm{~mm}$ (about one-seventh of the test shaft) and at a very short space, not more than $1.75 \mathrm{~mm}$, when the test shaft is $10.5 \mathrm{~mm}$.

These results support the opinion of Erlebacher and Sekuler (1969), that distances parallel to and near the test shaft may be more important than distances parallel but farther away. Pressey and Murray

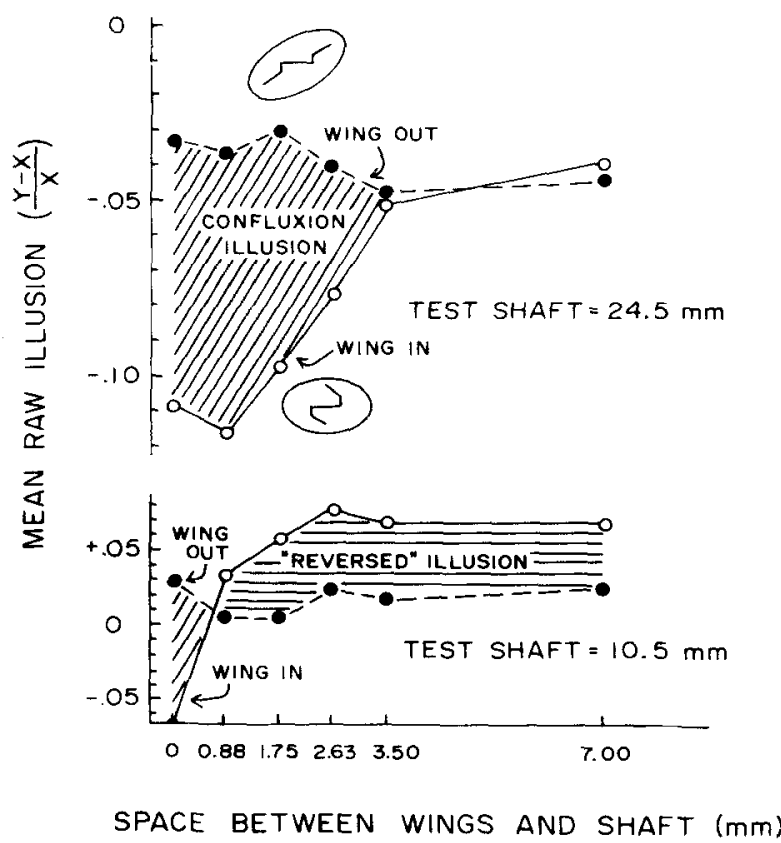

Figure 12. Mean raw illusion relative to shaft length as a function of vertical space between wings and shaft. Notice that the illusion disappears and even reverses with short spaces, one-seventh to even smaller proportion of the test shaft length. 
(1976) suggest that of distances from one end of the test shaft to the wing at the other end, those nearest the shaft should be most influential. If so, a spacer would push all the critical distances farther away from the test shaft, and therefore weaken the illusion. This is what happened in the experiment. Furthermore, a very short spacer, perhaps one-seventh of the length of the test shaft, is enough to abolish the illusion.

The effect of the spacer seems to be exerted mainly on the figure with wing in rather than with wing out.

It may be noticed that when the test shaft is $24.5 \mathrm{~mm}$ long, the illusions are always negative and may be over $11 \%$ negative. When the test shaft is $10.5 \mathrm{~mm}$ long, most of the responses are overestimations. Thus, it appears that when matching a long test shaft, subjects set $Y$ smaller than $X$, and when matching a shorter test shaft, they set $Y$ longer than $X$. This suggests a central-tendency effect, as if subjects adjusted $\mathrm{Y}$ not only to the $\mathrm{X}$ present but also to various memory stimuli. This is what would be expected if the subjects tended to set $Y$ to a "normal" value not entirely depending on the display presented at the time.

\section{EXPERIMENT 7}

The result of Experiment 6 tells us that the angle effect is decreased if the wing is separated from the ends of the test shaft. When so separated, the wing would still control the overall length of the test figure and would be available for confluxion effects that did not depend upon confusions at the ends of the test shaft. According to our analysis, this means that such left-over confluxion effects would operate only at the highest level of information processing, in the formation of judgments from lengths that had already been extracted from the image. The result of Experiment 6 suggests that there is no significant confluxion at this higher level, and this supports the hypothesis that the confluxion effect, which makes wings out increase $J(X)$ and wings in decrease it, is limited to a small area near the tips of the wings.

The purpose of Experiment 7 was to make a more direct confrontation of angles right at the tip of the test shaft against wings separated somewhat from the test shaft but controlling the overall length of the entire figure. To do this, each test shaft had attached to it a short wing at each end, and then to the tip of each inner wing was appended an outer wing, which varied in angle and length independently of the inner wing.

From this double-wing figure, we can hope to separate local effects near the tips of the shaft from more global effects controlling the total length of the displayed figure.

\section{Method}

Subjects, Apparatus, and Procedure. Ten new subjects from the summer-school pool were used in this experiment. The apparatus was as above, and the procedure involved a four-stimulus practice series followed by one random permutation of the 180 test stimuli described below. The experimenter inspected a summary data sheet from the four practice trials before beginning the main series, and was able to ensure that all subjects understood and conformed to the instructions.

Materials. Test shafts were of length 5.60 or $22.40 \mathrm{~mm}$. Inner wings were appended, as in previous experiments, at an angle of $20^{\circ}, 90^{\circ}$, or $160^{\circ}$ to the shaft and of length $0.00,0.70,1.40$, 2.80 , or $5.60 \mathrm{~mm}$. At the end of each inner wing was attached an outer wing set at an angle of $20^{\circ}$ or $160^{\circ}$ and of length 0.00 , 7.00 , or $17.50 \mathrm{~mm}$. These values were combined factorially into a 2 by 3 by 5 by 2 by 3 design producing 180 displays. The initial setting of the comparison line was always $3.50 \mathrm{~mm}$ longer than the test shaft.

\section{Results}

Averaged over the length and direction of the outer wings, the effects of inner wings in Figure 13 shows that the inner wings produce Mueller-Lyer illusion effects here much as they do without any outer wings. This suggests that these effects do not depend upon the overall length or size of the figure.

These displays permit a direct confrontation between inner and outer wings. In some of the displays, the

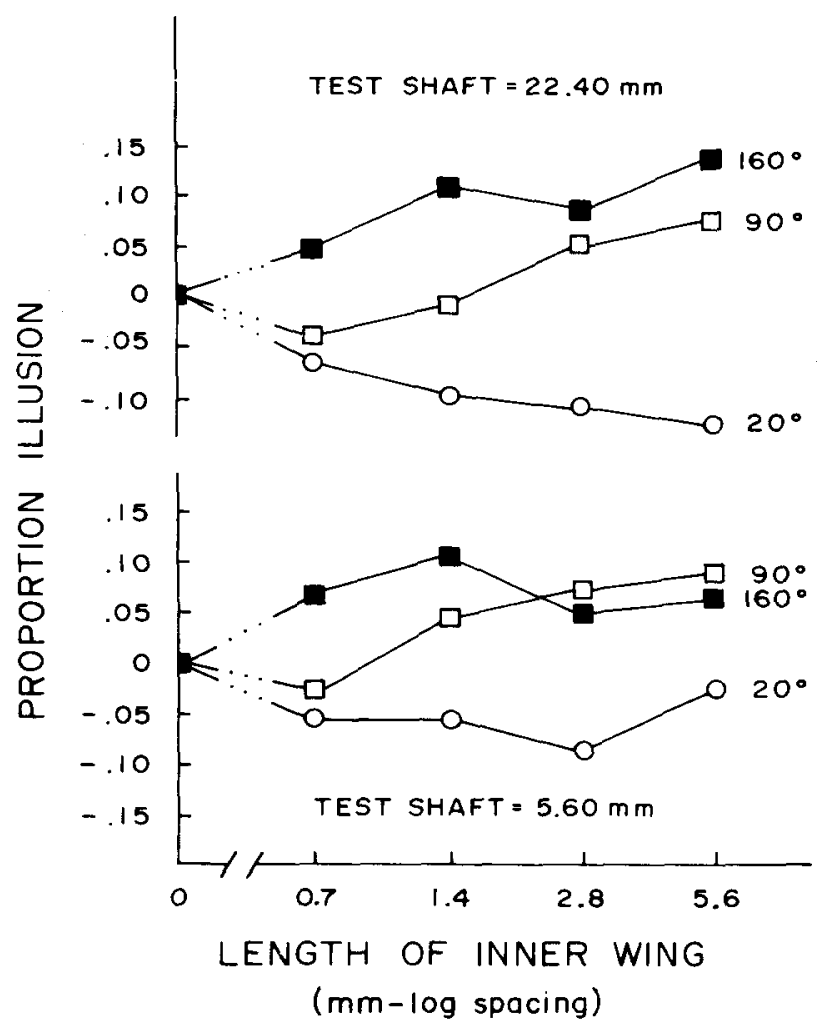

Figure 13. Proportional illusion as a function of length of inner wing in a figure with two segments of wing. These results are averaged over the three possible directions of the outer wing, $20^{\circ}, 90^{\circ}$, and $160^{\circ}$. 
inner wing is pointed in, the outer wing is pointed out. In some other displays, the inner wing points outward, the outer points in. In these displays, the two wings should produce opposite effects and their relative strengths can be compared.

Figure 14 shows the results of such an analysis. When the shaft is $22.4 \mathrm{~mm}$ long, the effects are relatively small. As the inner wing gets longer, the filled circles and squares go upward, and the open figures drop. This suggests that the inner wing is gaining relative influence as it gets longer, and the two are about equal when the inner wing is about $2.80 \mathrm{~mm}$ in length, approximately one-sixth of the test shaft. When the test shaft is short, the inner wings control the direction of the illusion in all cases, since solid figures are above open ones. When the outer wings are very long $(17.50 \mathrm{~mm})$ they seem to have very little effect, for the filled squares are much above the open squares in the lower panel.

These results are rather complex in form, but they reveal first that unless the inner wing is very short, it will tend to be more important than the long outer

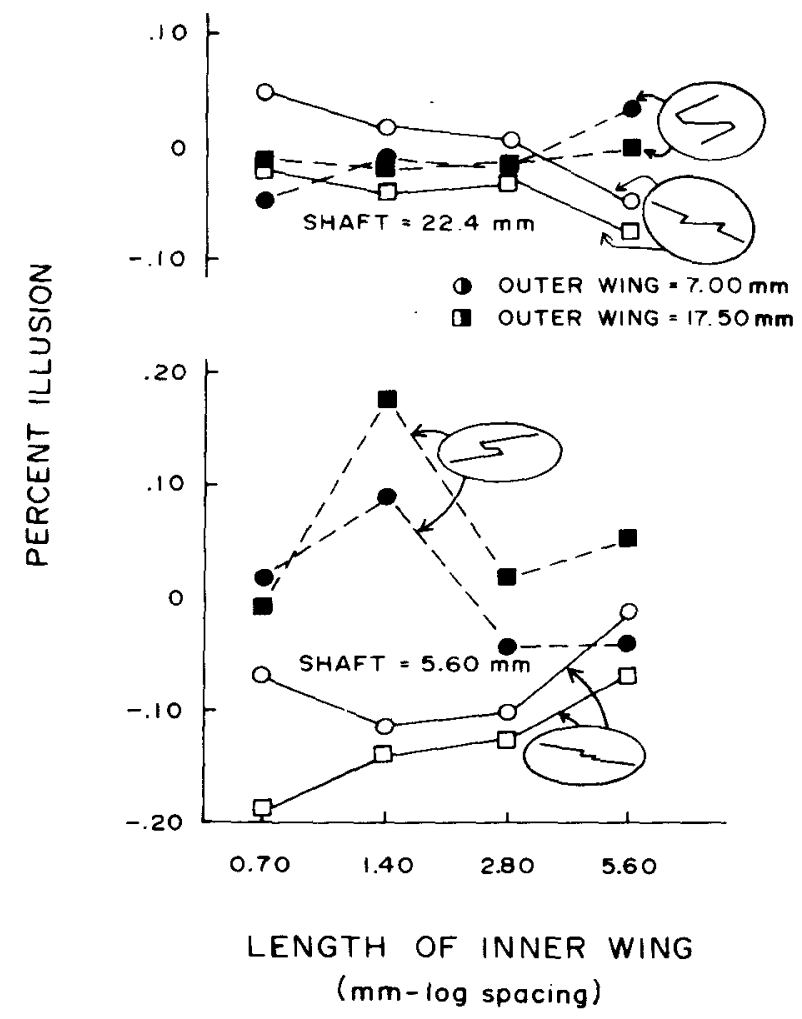

Figure 14. Conflicting effects of inner wing segments pointing one way with outer wing segments pointing the other, as a function of length of inner wing. Note that when the shaft is $22.4 \mathrm{~mm}$ and inner wings are $5.60 \mathrm{~mm}$, the inner wing dominates (solid dots are above open dots). When the shaft is only $5.60 \mathrm{~mm}$, then the greatest dominance of inner wings appears when the inner wing is $1.40 \mathrm{~mm}$. In both cases, then, the inner wing is most dominant when it is $25 \%$ the length of the test shaft. wing. A pattern arising in the data is that wings that are many times longer than the test shaft (i.e., $17.50 \mathrm{~mm}$ outer wings when the test shaft is only $5.60 \mathrm{~mm}$ ) or many times shorter (i.e., $0.70 \mathrm{~mm}$ inner wings when the test shaft is $22.40 \mathrm{~mm}$ ) are ineffective.

Experiments 6 and 7 together indicate that most of the usual Mueller-Lyer effect, the difference between wings-out and wings-in displays, depends on the wings attached to the tips of the test lines. There is some effect of longer wings that are separated a small distance from the ends of the test shaft, but if that separation is as much as $1 / 10$ th the length of the test shaft, the effect is essentially dissipated.

\section{GENERAL DISCUSSION}

The results of these seven experiments along with earlier quantitative studies of the length and angle of wings in the Mueller-Lyer figure, reveal sufficient complexity that we may question any of the usual simple "explanations" of the Mueller-Lyer figure.

There appear to be three main factors producing the various illusions we have demonstrated. One is a "confusion" effect that produces a difference between wings in and wings" out, and acts only if the wings are very close to the tips of the test shaft. This effect apparently increases with the length of the wings but only up to relatively short wings, perhaps up to half the shaft length. Second is an inverted-U function of wing length, symmetrical in log $\mathrm{W}$ and with a maximum positive illusion when wing length equals shaft length. Third is an effect of total figure size; the figure length with wings out equals $X-2 W \cos \theta$. It appears that when the figure is very long relative to the test shaft, the shaft appears short.

As a general conclusion, these experiments did not provide any evidence for distortion of the image, for they did not demonstrate any effects that produce an illusion of fixed retinal angle. This does not eliminate retinal induction or lateral inhibition as facts, but the present studies failed to show that such mechanisms play a major role in generating the Mueller-Lyer illusion under our free viewing conditions.

The same experiments do show a confluxion or confusion effect that depends on wings pointing in or out near the tips of the test shaft. This factor is mainly responsible for the difference between the wings-out and wings-in figures, the usual MuellerLyer illusion. This illusion, in our terms, occurs in the process of coding the image into information relevant to length, and may be involved with eye movements.

When long wings are used in a very obtuse wingsout figure, the illusion, instead of being very positive, turns negative. Equally negative illusions are found with very long wings folded inward. This may result from a contrast effect, the test shaft being seen within 
a very long total figure. Another phrase for such an effect is framing or enclosure (Fellows, 1968), for these very long wings produce a large total figure within which the test shaft is judged small. This effect is distinct from, and reverses, the confusion effect, and must be considered a second factor.

When wings are affixed at $90^{\circ}$ to the test shaft, retinal image distortion should not depend on the length of the wings. There is little excuse for confusion as to the length of the figure or test shaft, for that length is unaffected by wing length. However, the data show an inverted- $U$ function with a maximum illusion of about $5 \%$ when wing length, W, equals test shaft, $\mathrm{X}$. This inverted- $\mathrm{U}$ function appeared as a component in all acute-angle figures and all obtuse figures up to about $130^{\circ}$. This factor appears to arise at a judgmental level, after length information has been encoded and in the process of combining various items of length information into a final judgment. In fact, of course, the lengths involved, length of wing and length of test shaft, are perpendicular to one another, indicating that such lengths are commensurate. Mathematical analysis showed that such a factor could arise either from assimilation (Pressey \& Murray, 1976) or adaptation level (Restle, 1977).

These results are essentially neutral with respect to many theories which do not predict the effects of varying quantitative dimensions of the display. However, they do suggest that care must be taken in interpreting special experiments to prove and disprove theories. First, effort should be made to trace out at least some quantitative hypotheses, if the result is to be called a theory of the Mueller-Lyer illusion. Second, there appear to be two or three factors acting in these displays. This means that one cannot dispose of a possible causal factor by removing it and showing that the illusion still exists. Such an argument is used, for example, if one disposes of the idea that the Mueller-Lyer illusion arises from distortions of angles by showing that the illusion still exists when circular arcs replace the wings, and there are no angles. Such an experiment may remove one factor producing the illusion but leave others, and therefore still leave an illusion. Step by step, a research program would be able to eliminate all causes, leaving us with no theory at all. If several factors are involved, as appears likely from the present results, removal of even an important factor may not eliminate the illusion.

Finally, it should be noted that combining the data from several old experiments with our newer data does not reveal any serious discrepancy. This paper does not join in the tradition of dismissing earlier work on vague methodological grounds, as do Dewar (1967) and Lewis (1909), and especially would not criticize the exceptionally well-organized studies of Heymans (1896). It appears that, in this area of research, one should attempt a reconciliation of all of the relevant data with any theoretical proposals.

\section{REFERENCES}

Biervliet, J. J. van. Nouvelles mésures des illusions visuelles chez les adultes et chez les enfants. Revue Philosophique, 1896, 41, 169-181.

COREN, S. Lateral inhibition and geometric illusions. Quarterly Journal of Experimental Psychology, 1970, 22, 274-278.

Coren, S., Girgus, J. S., Erlichman, H., \& Hakstian, A. R. An empirical taxonomy of visual illusions. Perception \& Psychophysics, 1976, 20, 129-137.

Coren, S., \& Hoenig, P. Effect of non-target stimuli upon length of voluntary saccades. Perceptual and Motor Skills, 1972, 34, $499-508$.

DEWAR, R. E. Stimulus determinants of the magnitude of the Müller-Lyer illusion. Perceptual and Motor Skills, 1967, 24, 708-710.

ERLebacher, A., \& Sekuler, R. Explanation of the Müller-Lyer illusion: Confusion theory examined. Journal of Experimental Psychology, 1969, 80, 462-467.

Fellows, B. J. The reverse Müller-Lyer illusion and "enclosure." British Journal of Psychology, 1968, 59, 369-372.

Festinger, L., White, C. W., \& Allyn, M. R. Eye movements and decrement in the Müller-Lyer illusion. Perception \& Psychophysics, 1968, 3, 376-382.

Fisher, G. H. An experimental and theoretical appraisal of the perspective and size constancy theories of illusions. Quarterly Journal of Experimental Psychology, 1970, 22, 631-652.

Green, R. T., \& Hoyle, E. M. Adaptation level and the opticogeometric illusions. Nature, 1964, 201, 1200-1201.

Hermans, G. Untersuchunger über das "optischen Parodoxen." Zeitschrift für Psychologie, 1896, 9, 221-225.

JudD, C. H. The Müller-Lyer illusion. Psychological Review Monograph Supplement, 1905, 7(Whole No. 29), 55-81.

KaUfman, L., \& Richards, W. Spontaneous fixation tendencies for visual forms. Perception \& Psychophysics, 1969, 5, 85-88.

LEwIs, E. O. Confluxion and contrast effects in the Müller-Lyer illusion. British Journal of Psychology, 1909, 3, 21-41.

Mclaughlin, S. C.. DeSisto. M. J., \& Kelley, M. J. Comment on "Eye movement and decrement in the Müller-Lyer illusion." Perception \& Psychophysics, 1969, 5, 288.

MüLLER-LyER, F. C. Zur Lehre von den optischen Tauschungen. Über Kontrast und Konfluxion. Zeitschrift für Psychologie, 1896, 9, 1-16. (a)

Müller-LyER, F. C. Über Kontrast und Konfluxion (Zweiter Artikel). Zeitschrift für Psychologie, 189, 10, 421-431. (b)

NAKAGAWA, D. Müller-Lyer illusion and retinal induction. Psychologia, 1958, 1, 167-174.

Pí́ron. H. L'illusion de Müller-Lyer et son double méchanisme. Revue Philosophique, 1911, 71, 245-284.

Pressey, A. W. A theory of the Müller-Lyer illusion. Perceptual and Motor Skills, 1967, 25, 569-572.

Pressey, A. W. The assimiliation theory applied to a modification of the Müller-Lyer illusion. Perception \& Psychophysics, 1970 , 8, 411-412.

Pressey, A. W., \& Murray, W. Further developments in the assimilation theory of geometric illusions: The adjacency principle. Perception \& Psychophysics, 1976, 19, 536-544.

Restle, F. Visual illusions. In M. H. Appley (Ed.), Adaptationlevel theory. New York: Academic Press, 1971.

Restle, F. Assimilation produced by contrast. In N. J. Castellan \& F. Restle (Eds.), Cognitive theory (Vol. 3). Hillsdale, N.J: Erlbaum, 1977.

Richards, W., \& Kaufman, L. "Center-of-gravity" tendencies for fixations and flow patterns. Perception \& Psychophysics, 1969, 5, 81-84.

SARRIs, V. Effects of stimulus-range and anchor value on psychophysical judgment. In H. G. Geissler \& Yu. M. Zabrodin (Eds.), Advances in psychophysics. Berlin: V E B Deutscher Verlag der Wissenschaften, 1976

VIRsu, V. Contrast and confluxion as components in geometric illusions. Quarterly Journal of Experimental Psychology, 1967, 
19. 198-207.

VIRSU, V. Tendencies to eye movement, and misperception of curvature, direction, and length. Perception \& Psychophysics, $1971,9.65-72$.

W AGNER, H. L. "The illusions and Ganz's theory of contour displacements." British Journal of Psychology, 1968, 58, 361-368.

\section{NOTE}

1. However, Pressey (1970) gives an interpretation of this sort of figure that considers assimilation between the test shaft and the length of an imaginary line drawn from one end of the test shaft to the end of the wing extending from the other end of the test shaft. The length of this imaginary line, in the case of the $90^{\circ}$ figure, is $D=\left(X^{2}+W^{2}\right)^{1 / 2}$, and the apparent length of the test shaft would lie between $D$ and $X$. This formulation would agree with the upward part of the inverted- $U$ function, but must be modified to produce the downward part found with long wings.

(Received for publication October 25, 1976; revision accepted February 21, 1977.) 